\title{
Sythesis of bioavture through hydrodeoxygenation and catalytic cracking from oleic acid using NiMo/Zeolit catalyst
}

\author{
Michelle Flavin Carli ${ }^{1}$, Bambang Heru Susanto ${ }^{1, *}$, and Thareq Kemal Habibie ${ }^{1}$ \\ ${ }^{1}$ Chemical Engineering Department, University of Indonesia, Kampus Baru Universitas Indonesia, Depok 16424;
}

\begin{abstract}
Currently, fossil fuels are still the primary source of fuel. As has been known, fossil fuel especially aviation fuel is limited resources and can increase greenhouse gas emissions. This condition encourages replacement efforts of avture into bioavture fuel. In this research, bioavture is synthesized through hydrodeoxygenation and catalytic cracking from oleic acid as a model compound using NiMo/Zeolite catalyst. Hydrodeoxygenation carried out under operating conditions: at temperature of $375^{\circ} \mathrm{C}$, under 15 bar pressure and for 2.5 hours. The chain of hydrocarbons from the result of hydrodeoxygenation has been cracked by catalytic cracking reaction for 1.5 hours. Variation operating condition used are 360,375 , and $390^{\circ} \mathrm{C}$. The liquid product is tested its chemical characteristic, ie acid number, FTIR and GC-MS and its physical characteristics, ie density test and viscosity. Bioavtur that synthesized by catalytic cracking have met the specifications of bioavtur, except the acid number with optimum temperature at $375^{\circ} \mathrm{C}$. These conditions with $\mathrm{NiMo} /$ Zeolite activated led to dominant yield of $36.32 \%$, selectivity of $38.05 \%$, and conversion of $84.30 \%$. Percentage of yield and selectivity of bioavtur are still low caused by performance of catalyst that is still can not optimum. While, high percentage of conversion caused by high temperature used for catalytic cracking.
\end{abstract}

\section{Introduction}

Every year, the national energy sector always faces challenges in the utilization of fossil fuels especially fuel oil, which shows the increase of consumption continually. One of fuel oil is the aviation fuel, commonly called avture or jet fuel. From 2005 to 2011, the consumption of aviation fuel in Indonesia is almost always greater than the production that must be fulfilled through imports. Indonesia's aviation fuel consumption in 2014 reached 4.2 million kiloliters (KL) while production from domestic refineries reached only 3.3 million KL, so the balance of aviation commodities recorded a deficit of 0.9 million KL [1]. This condition encourages the search effort of alternative aviation fuels as a substitute for petroleum-based energy supply.

As has been known, bioavture is a fuel aircraft similar avture (aviation turbine) which generally use vegetable oil as raw materials. One of the most abundant vegetable oils in Indonesia and widely used as feedstock for biofuel production is palm oil.

Source of raw materials used for bioavture production in this study is a compound model one of the unsaturated fatty acids contained in vegetable oil, namely oleic acid $\left(\mathrm{C}_{18} \mathrm{H}_{34} \mathrm{O}_{2}\right)$. The use of oleic acid as a raw material aims to represent one of the double bonds of fatty acids contained in vegetable oils, thereby the characterization of bioavture production process, optimum operating conditions, and pathways of reaction can be obtained easier and these parameters can be used as reference for conversion vegetable oils to bioavtures.
Oleic acid can be converted by some methods, such as thermal cracking, catalytic cracking, hydrocracking, hydrodeoxygenation, etc.

In this research, oleic acid converted by hydrodeoxygenation and catalytic cracking. Hydrodeoxygenation method is a hydrogenolysis process that aims to remove oxygen from a material buy cutting off the carbon-oxygen bonds using hydrogen pressure. During the hydrodeoxygenation (HDO) process, oils and fats essentially consisting of triglycerides, which are molecules with higher levels of oxygen, are subjected to high $\mathrm{H}_{2}$ pressures and high temperatures in the presence of metal catalysts. At the end of the process, n-paraffins are produced as the constituents of gasoline, jet fuel, and diesel. The principal chemical reactions that occur during the HDO process are: decarboxylation, decarbonylation, and hydrogenation [2].

Decarboxylation reaction is the expected reaction during the hydrodeoxyygenation process. Decarboxylation is the reaction of the breaking of the carboxylic bond in the vegetable oil. The success of the decarboxylation is the parameter of success in generating bioavtures. Cabon dioxides gas produced during the production process is the number of carboxylate groups that have been disconnected from the reactants.

Meanwhile, catalytic cracking is reaction breakdown of hydrocarbon compounds that have large molecules into smaller molecules at high temperatures with the aid of a catalyst. The process of catalytic cracking is a simple method and effective for the manufacture of biofuel [3]. In the catalytic process of the compound

\footnotetext{
* Corresponding author: bambanghs@che.ui.ac.id
} 
with high molecular weight in raw material will be break down into compounds with a small molecular weight such as gasoline, kerosene, and diesel with use catalyst [4] [5].

Commonly used catalysts are nickel metal catalyst (Ni) and molybdenum (Mo). The core of catalyst needs to be distributed on a surface of support catalyst, one of which is zeolite. The use of zeolite as a support catalyst is due to three-dimensional structure of a highly porous zeolite and has a fairly wide pore space which is indicated by the large volume and pore diameter of the zeolite [6]. The type of zeolite used in this study is natural zeolite, because of its abundant availability in nature an has an affordable price.

\section{Methodology}

\subsection{Materials}

The materials used in this experiment are: Oleic Acid Technical Grade was purchased from TnT Chemical (Bandung, Indonesia), NiMo/Zeolite, ethanol (Merck), barium hydroxide (Merck), phenolphthalein (Merck), kalium phtalat (Merck), and aquadest (Merck).

\subsection{Hydrodeoxygenation}

Hydrodeoxygenation was performed in $330 \mathrm{~mL}$ batch stirred autoclave reactor integrated with a condenser and furnace. Extensive stirring of the oil and water in the reactor was achieved using a magnetically driven stirrer with a DC geared motor. Nitrogen gas purged for 30 minutes. To ensure the activity of catalyst, $1.5 \mathrm{~g}$ $\mathrm{NiMo} /$ Zeolit which has been prepared by impregnation method was maintained in the reactor at $300{ }^{\circ} \mathrm{C}$ under 10 bar of $\mathrm{H}_{2}$ pressure for $1 \mathrm{~h}$. After that, $150 \mathrm{ml}$ oleic acid was added. The mixture was heated to $375^{\circ} \mathrm{C}$ under 15 bar of $\mathrm{H}_{2}$ pressure for $2.5 \mathrm{~h}$. Stirrer speed during the reaction was kept constant at $800 \mathrm{rpm}$. To check the reaction has occurred or not, the gas product was taken every 15 minutes and tested with GC-TCD. In this step, the double bonds and the oxygen that were present in the triglycerides were saturated with hydrogen gas. The gas products were condensed and collected as condensate.

\subsection{Catalytic Cracking}

Catalytic cracking was performed in the same reactor with same equipment as hydrodeoxygenation. Hydrodeoxygenation product and $\mathrm{NiMo} /$ Zeolite catalyst was used as feed with ratio of 100:1 \%wt. Nitrogen gas purged for 30 minutes. Stirrer speed during the reaction was kept constant at $800 \mathrm{rpm}$. The reaction has three different operating condition i.e. $360^{\circ} \mathrm{C}, 375^{\circ} \mathrm{C}$ and $390^{\circ} \mathrm{C}$. The temperature of the reactor reached was adjusted to desired value. The reaction was occurred for $1.5 \mathrm{~h}$.. In this step, the chain of hydrocarbons of hydrodeoxygenation product were cracked into shorter chain.. The gas products were condensed and collected as condensate. The bottom product was distilled according to the boiling range of petroleum products in three categories i.e. IBP- $200^{\circ} \mathrm{C}, 200-300^{\circ} \mathrm{C}$, and 300 -EP [7].

\subsection{Characterization of HDO and CC Product}

Hydrodeoxygenation and catalytic cracking products were characterized by GC-MS (Agilent) to identify fraction component of sample, FTIR (Termo Scientific) to know the functional groups of the product, and GCTCD to know the gas consumption and formation. Chemical properties of bioavtur were investigated through acid number to know the amount of free fatty acids in the products. Acid numbers were determined by titration with $\mathrm{KOH}$. The samples were assayed in triplicate and the analysis was conducted in accordance with ASTM D3242. Physical properties of bioavtur were investigated through density, and viscosity to know the quality of the products.

\section{Result and Discussion}

\subsection{Synthesis of Bioavture}

Products produced from synthesis through hydrodeoxygenation and catalytic cracking reaction is divided into two, top product formed in the gas form and bottom product in the liquid form. Then, bottom product that have been distilled is characterized to determine the optimum operating condition.

\subsubsection{Density of Bioavtur}

Physical properties that become one of the parameters in the quality of fuel is the density, which is the unit of fuel weight per unit volume.

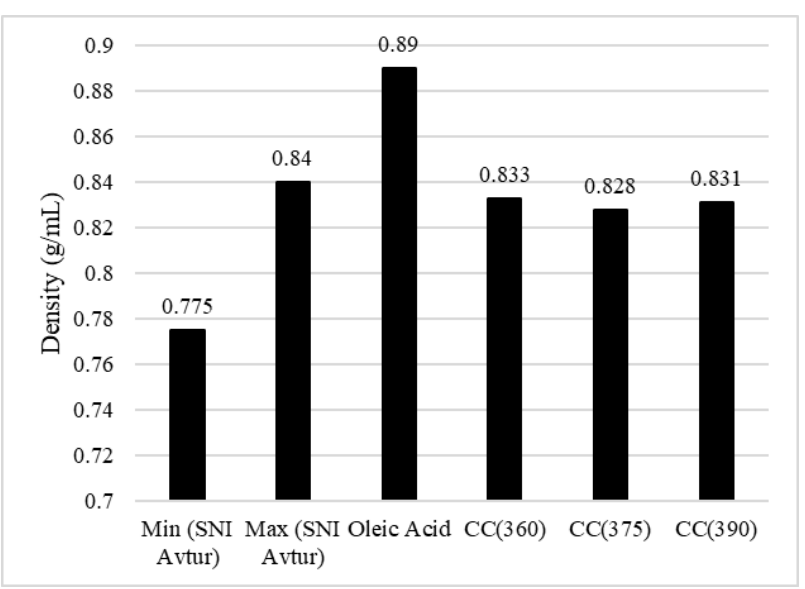

Fig. 1. Comparison of Density

Figure 1 shows the decrease in density from raw material in the form of oleic acid to bioavture. This change indicates that hydrodeoxygenation and catalytic cracking reactios has occured over the NiMo/Zeolite catalyst. The decrease in the density value due to long carbon chain bonds in the oleic acid has been broken into short carbon chains so that the molecular weight of bioavture products will decrease. From Figure 1, we can 
also see that catalytic at $375^{\circ} \mathrm{C}$ has better density than catalytic cracking at $360^{\circ} \mathrm{C}$ and $390^{\circ} \mathrm{C}$ and meets the specifications of commercial avtur..

\subsubsection{Viscosity of Bioavtur}

Viscosity is a resistivity parameter possessed by a fluid discharged in a capillary tube, expressed in units of time required to travel a certain distance.

Figure 2 shows that the product's viscosity of catalytic cracking at 360,375 and $390^{\circ} \mathrm{C}$ are respectively $3.50,3.37$ and 2.93 which are still in the range of commercial avtur viscosity reffering to ASTM D1655. The graps also shows the decrease in viscosity from raw material in the form of oleic acid to bioavture. The decrease of viscosity caused by the breaking of carboxylic bond from the waste cooking oil containing carbonyl (CO) and hydroxyl $(-\mathrm{OH})$. The presence of a hydroxyl group on a carboxylic bond may form a hydrogen bond with a carbonyl group that causes the bonding between molecules become stronger and higher viscosity value [8].

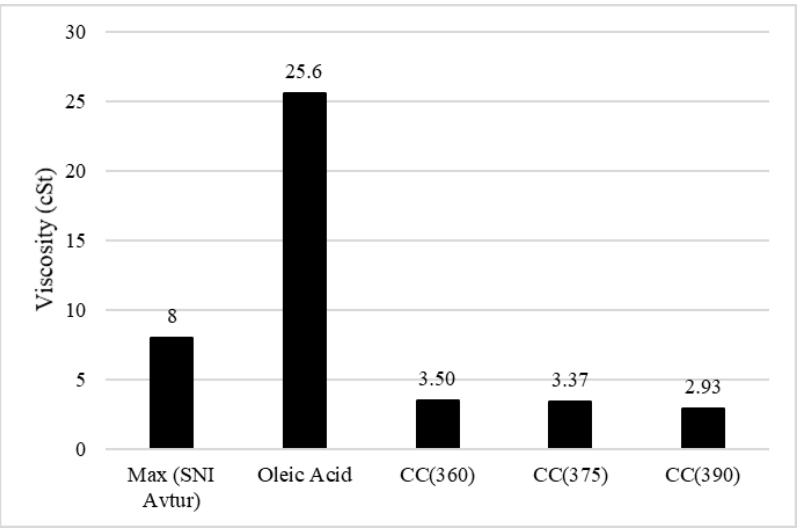

Fig. 2. Comparison of Viscosity

\subsubsection{Acid Number of Bioavtur}

The higher the acid number indicates that there are still many free fatty acids in a sample.

Figure 3 shows that all products of bioavture have not met the specifications of avture based on Indonesia National Standard (SNI) for the acid number parameter. It means that there are still many free fatty acids that have not been converted into alkanes, so the reactions have not run optimally. Figure 3 also shows a decrease in the value of the acid number in the products, indicates the catalytic cracking occured well and cracked the carboxylic acid group contained in the raw material into alkane hydrocarbons.

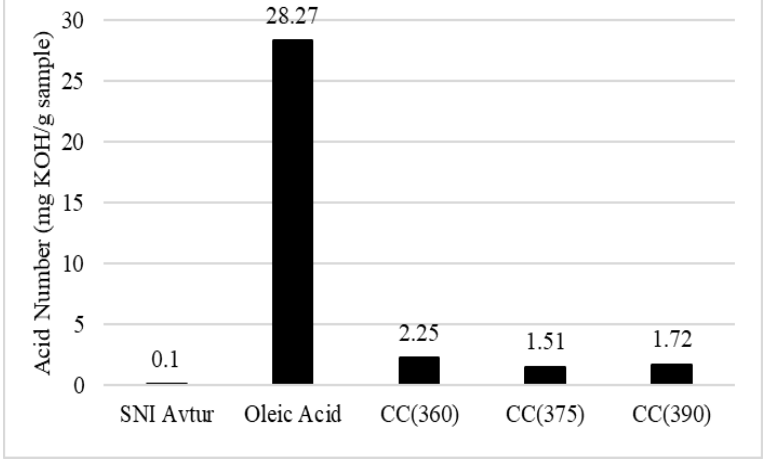

Fig. 3. Comparison of Acid Number

\subsubsection{Fouried-Transform Infrared Spectroscopy}

The functional groups of hydrodeoxygenation and catalytic cracking products are detected by FTIR. In Fig. 4 , it can be seen that oleic acid, hydrodeoxygenation product, and catalytic cracking products which is bioavture, have absorption at the wavelength range of $2921 \mathrm{~cm}^{-1}$, indicates the presence of alkane group (C-H). From Table 1, it can be seen that the decrease of the transmittance value of the alkane group is followed by the increase of the transmittance value of the alkene group. This change indicates that the alkenes have been cracked become alkane groups.

Table 1 also shows on the raw material and bioavture product, there are carbonyl group $(\mathrm{C}=\mathrm{O})$ which read at the wavelength of $1700-1750 \mathrm{~cm}^{-1}$, where there is a significant increase of transmittance value from raw material in the form of oleic acid to the final product of bioavture. This indicates that the carboxylate group has been cracked in the raw material. However, once those peaks did not disappear completely, it means that there was no full conversion when using the tested experimental conditions.

\subsubsection{Gas Chromatography-Mass Spectroscopy}

To evaluate the compounds synthesized in the HDO and $\mathrm{CC}$ reactions, the gas chromatography technique coupled with mass spectrometry was used.

The CC reaction products can be used to formulate biogasoline (5 to 8 carbon atoms), jet fuel ( 9 to 15 carbon atoms), green diesel (16 to 20 carbon atoms) and lubricant (21 to 25 carbon atoms) [9]. The semiquantitative proportions of these biofuels were calculated using GCMS data and hydrocarbon chain sizes. The result are shown in Table 2. 


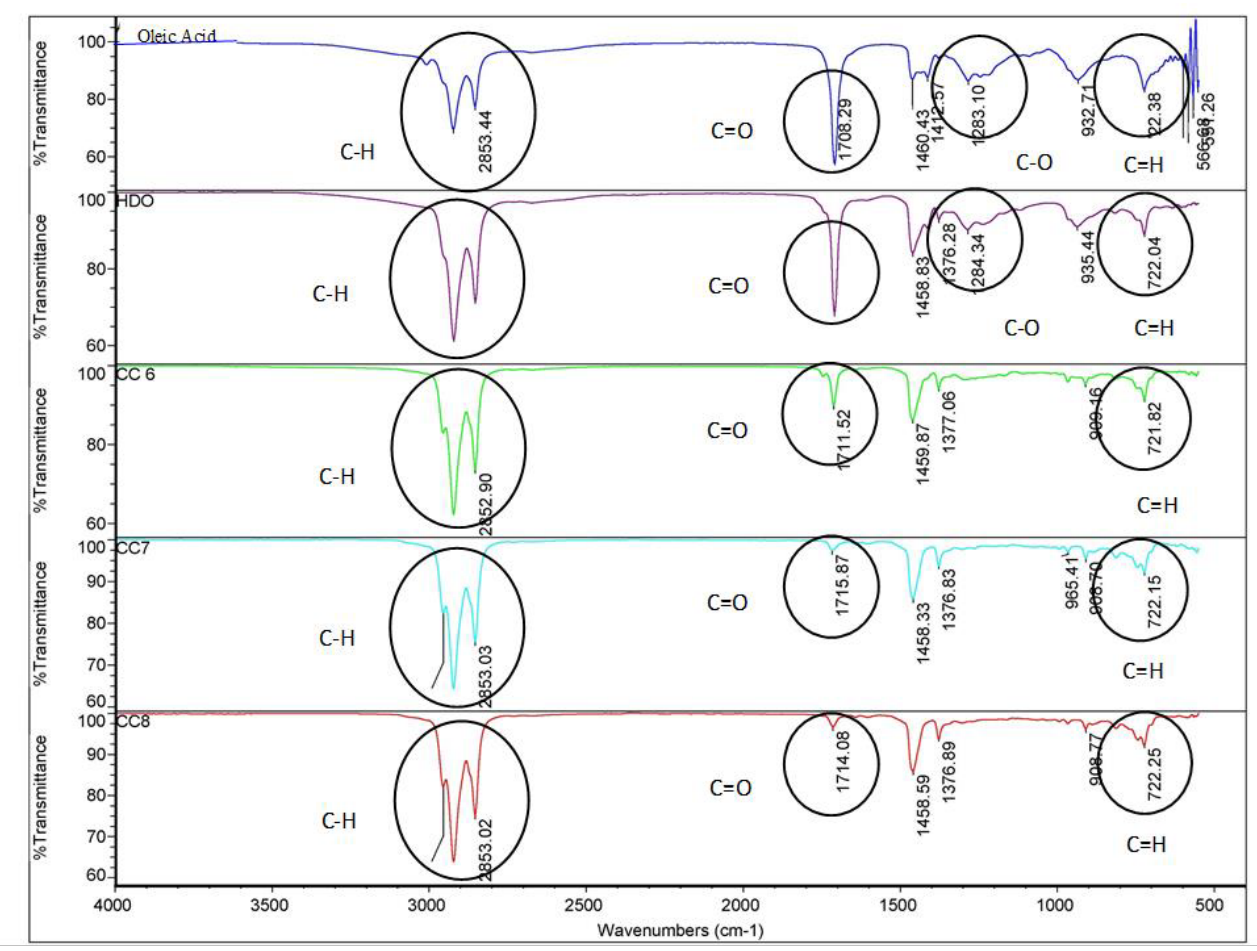

Fig. 4. FTIR Result

The percentage of green diesel composition still dominates, especially in product of $\mathrm{CC}(390)$. This result indicates that oleic acid have been converted into alkanes but the chain is still quite long. As for the percentage of biogasoline composition is still quite high, especially in product of $\mathrm{CC}(375)$. This phenomena can be caused by a more reactive thermal cracking reaction than catalytic cracking at high temperatures.

Table 1. FTIR Transmittance Comparison of Bioavture and Other Product

\begin{tabular}{|c|c|c|c|c|}
\hline \multirow{2}{*}{ Sample } & \multicolumn{4}{|c|}{ Transmittance (\%) } \\
\cline { 2 - 5 } & $\mathbf{C - H}$ & $\mathbf{C}=\mathbf{O}$ & $\mathbf{C - O}$ & $\mathbf{C = H}$ \\
\cline { 2 - 5 } & $\begin{array}{c}2830- \\
3000 \\
\mathrm{~cm}^{-1}\end{array}$ & $\begin{array}{c}1700- \\
1750 \\
\mathrm{~cm}^{-1}\end{array}$ & $\begin{array}{c}1100- \\
1300 \\
\mathrm{~cm}^{-1}\end{array}$ & $\begin{array}{c}675- \\
1000 \\
\mathrm{~cm}^{-1}\end{array}$ \\
\hline $\begin{array}{c}\mathrm{CC6} \\
\left(360^{\circ} \mathrm{C}\right)\end{array}$ & 62.306 & 89.916 & - & 91.475 \\
\hline $\begin{array}{c}\mathrm{CC7} \\
\left(375^{\circ} \mathrm{C}\right)\end{array}$ & 64.286 & 97.346 & - & 92.014 \\
\hline $\begin{array}{c}\mathrm{CC} 8 \\
\left(390^{\circ} \mathrm{C}\right)\end{array}$ & 63.810 & 96.686 & - & 92.100 \\
\hline HDO & 61.528 & 68.529 & 90.182 & 88.998 \\
\hline $\begin{array}{c}\text { Oleic } \\
\text { Acid }\end{array}$ & 69.465 & 57.505 & 86.329 & 83.236 \\
\hline
\end{tabular}

Table 2. GC-MS Results

\begin{tabular}{|c|c|c|}
\hline Sample & $\mathbf{C C ( 3 7 5 )}$ & $\mathbf{C C ( 3 9 0 )}$ \\
\hline Biogasoline & 13.90 & 4.95 \\
\hline Bioavture & 38.05 & 35.29 \\
\hline Green Diesel & 38.37 & 46.27 \\
\hline Lubricant & 4.45 & 4.13 \\
\hline
\end{tabular}

The results presented in Figure 5 shows that the oleic acid have good enough potential for the production of bioavture with range of yield is about $30 \%$. This result indicates that the $\mathrm{NiMo} / Z$ eolite catalyst used is less selective for producing bioavtures, both in catalytic cracking reactions and in hydrodeoxygenation reactions. In addition, less optimal yield and selectivity of bioavture in this study could also be due to the low ratio of catalysts used in the catalytic cracking reaction, ie $1 \%$.

Conversion, selectivity, and yield were also calculated using GCMS data. These are the success parameters of hydrodeoxygenation and catalytic cracking process in producing bioavtures. Fig.5 and Fig.6 show that the largest percentage of yield and selectivity of bioavtur occurred at CC(375). It means that the optimum temperature of catalytic cracking in this study achieved at $375^{\circ} \mathrm{C}$. While, from Figure 7 it can be seen that the CC(390) conversion value is higher than $\mathrm{CC}(375)$, because the higher temperature will induce the hydrodeoxygenation reaction and the catalytic cracking 
toward the product, especially the endothermic reaction. In addition, high temperatures will also cause a thermal cracking reaction that can increase the number of products.

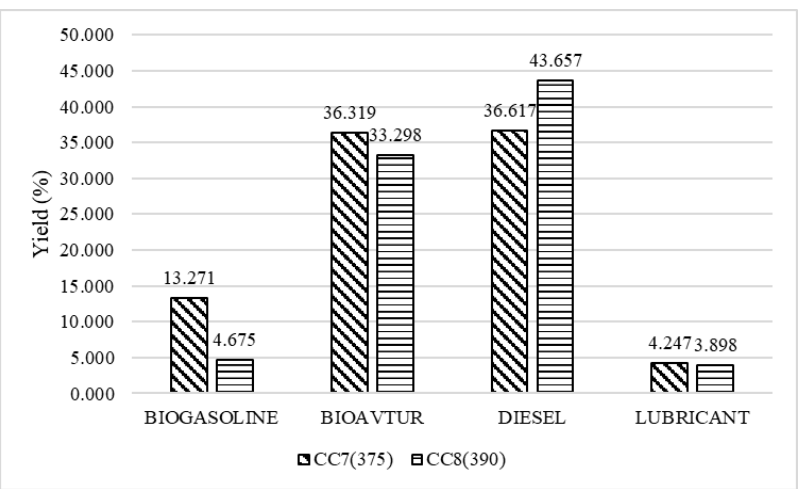

Fig. 5. Yield Comparison of Catalytic Cracking Product

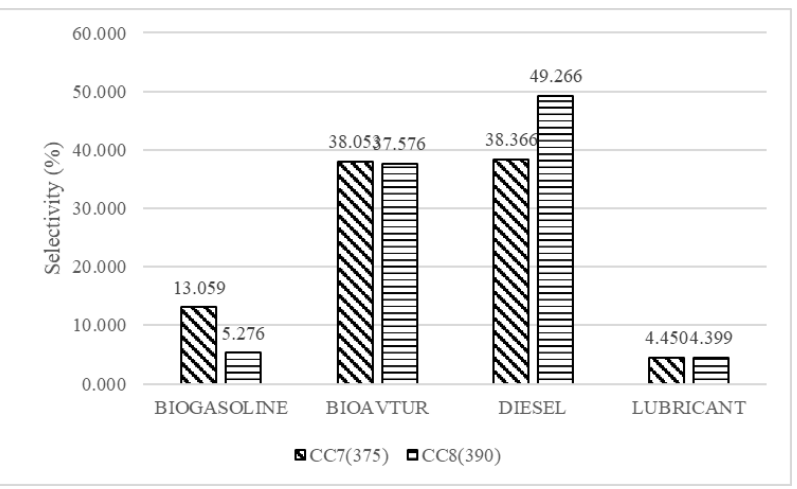

Fig. 6. Selevtivity Comparison of Catalytic Product

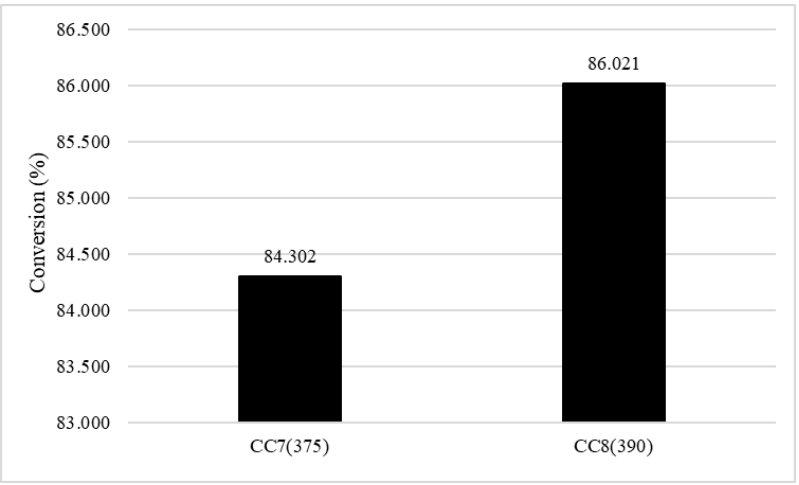

Fig. 7. Conversion Comparison of Catalytic Product

\section{Conclusion}

Characterizations of bioavture have shown that hydrodeoxygenation and catalytic cracking products have met the specifications of bioavtur, except the acid number with optimum temperature at $375^{\circ} \mathrm{C}$. These conditions with $\mathrm{NiMo} /$ Zeolit activated led to dominant yield of $36.319 \%$ of bioavture fraction, selectivity of $38.053 \%$, and conversion of $84.302 \%$. This study has shown the optimum temperature of catalytic cracking for bioavture synthesis, but the catalysts used are less selective, both in hydrodeoxygenation and catalytic cracking reactions. So it is necessary to re-research to find a more selective catalyst for bioavture synthesis.

Director of Research and Community Service through International Indexed Publication Grant for Student Thesis (PITTA) Universitas Indonesia 2018 with contract No. 2388/UN2.R3.1/HKP.05.00/2018 is acknowledged for the financial support to carry out the present study.

\section{References}

1. D. E. Nasional, "Outlook Energi Indonesia 2016," Sekretariat Jenderal Dewan Energi Nasional, 2016.

2. S. M Krar, L. Kovacs, L. Boda, A. Leveles, Thernesz, J. Wahlne and Hancsok, "Fuel Purpose Hydrotreating of Vegetable Oil on NiMo/A12O3 Catalyst," pp. 107111, 2009.

3. S. Hassan, Y. Sani, A. A. R. Abdul, N. Sulaiman and W. M. A. W. Daud, "Biogasoline: an out of the box solution to the food for fuel and land use competitions," Energy Conversion and Management, vol. 89, pp. 349-367, 2015.

4. Y. K. Ong and S. Bhatia, "The current status and prespectives of biofuel production via catalytic cracking of edible and non edible oils," Energy, vol. 35, pp. 111-110, 2010.

5. Nurjannah, A. Roesyadi and D. H. Prajitno, "Biofuel Production from Catalytic Cracking of Palm Oil," Jurnal Reaktor, vol. 13, pp. 37-43, 2010.

6. B. Bognadov, D. Georgiev, I. Markovska and Y. Hristov, "Synthetic Zeolites: Structure, Clasification, Current Trends in Zeolite Synthesis Review," International Science Conference, 2009.

7. B. H. Susanto, M. Nasikin and A. Wiyo, "Synthesis of Renewable Diesel through Hydrodeoxygenation Using Pd/Zeolite Catalysts," Procedia Chemical, vol. 9, p. 1390150, 2014.

8. B. H. Susanto, M. B. Prakasa and M. Nasikin, "Synthesis of Renewable Diesel from Palm Oil and Jatropha Curcas Oil Through Hydrodeoxygenation Using NiMo/ZAL," International Journal of Technology, Depok, 2016.

9. F. De Sousa, C. Cardoso and V. Pasa, "Producing Hydrocarbons for Green Diesel and Jet Fuel Formulation from Palm Kernel Fat Over Pd/C," Fuel Processing Technology, p. 143, 2016. 